\title{
Accumulated HSV1-TK Proteins Interfere with Spermatogenesis through a Disruption of the Integrity of Sertoli-Germ Cell Junctions
}

\author{
Li-Yi CAI 1,2,3)*, Takako KATO2)*, Mo CHEN ${ }^{3)}$, HongHua WANG ${ }^{1)}$, Ei-ichiro SEKINE"), \\ Shun-ichiro IZUMI ${ }^{5)}$ and Yukio KATO ${ }^{2,3,4)}$ \\ 1) Department of Reproductive Medicine, The Affiliated Wuxi Hospital for Maternal and Children Health Care of Nanjing \\ Medical University, Jiangsu Province 214002, China \\ ${ }^{2)}$ Institute of Reproduction and Endocrinology, Meiji University, Kanagawa 214-8571, Japan \\ 3) Division of Life Science, Graduate School of Agriculture, Meiji University, Kanagawa 214-8571, Japan \\ 4) Laboratory of Molecular Biology and Gene Regulation, Department of Life Science, Meiji University, Kanagawa \\ 214-8571, Japan \\ ${ }^{5)}$ Department of Obstetrics and Gynecology, Tokai University School of Medicine, Kanagawa 259-1193, Japan
}

\begin{abstract}
Transgenic rats show spermatid-specific ectopic expression of the reporter gene, herpes simplex virus type1 thymidine kinase (HSV1-TK), in the testes and have demonstrated male infertility. However, the disruption of spermatogenesis and the underlying molecular mechanisms in these transgenic animals have not been well clarified. In this study, light and electron microscopic observations were performed to characterize the morphological changes in the testes. To explore the molecular mechanisms of male infertility in the HSV1-TK transgenic rat, cDNA microarray and quantitative real-time PCR analyses were performed. The seminiferous tubules of 3-month-old transgenic rats showed morphological alterations including seminiferous epithelial sloughing, vacuolization, and degeneration of spermatogenic cells, suggesting a failure of Sertoli-germ cell interaction. Components of the epididymal lumen from transgenic rats included abnormal spermatozoa, degenerating round spermatids and abnormal elongated spermatids indicating an appearance of direct impairment of spermiogenesis. cDNA microarray and real-time PCRanalyses revealed significant changes $(\mathrm{P}<0.05)$ in the gene expression level in six genes, testin, versican, mamdc1, fgf7, ostf1 and cnot7. Among them, testin drew most of our attention, since the testin gene is a sensitive marker for disruption of Sertoli-germ cell adhesion. Thus, our results suggest that the accumulation of HSV1-TK in the spermatids not only directly interferes with spermiogenesis but also disrupts spermatogenesis through a disruption of Sertoligerm cell adhesions. It is important to explore the testicular actions of the HSV1-TK protein in transgenic experimental models and thereby gain clues to find an appropriate treatment for HSV-infected patients exhibiting human male infertility, as has been recently observed.
\end{abstract}

Key words: HSV1-TK, Infertility, Spermatogenesis, Testin, Transgenic rat

(J. Reprod. Dev. 58: 544-551, 2012)

A suicide gene system, herpes simplex virus type 1 thymidine kinase (HSV1-TK) and its specific substrate, ganciclovir, is widely used for cancer therapy $[1,2]$. However, previous investigators also reported that HSV1-TK proteins are likely to play a toxic role in the developing mouse male germ cells in the absence of the nucleoside analog, ganciclovir, to induce defects in cell proliferation [3-6]. The major histological defects of HSV1-TK transgenic mice appeared to be an abnormal nuclear morphology of elongating spermatids and electron microscopy observation disclosed insufficient chromatin condensation and abnormal acrosome structures [4]. Al-Shawi et al. demonstrated that truncated TK polypeptides are translated mainly in the haploid spermatids by a cryptic TATA box-independent promoter and that the severity of male infertility depended on the level of

Received: October 17, 2011

Accepted: May 10, 2012

Published online in J-STAGE: June 14, 2012

(C)2012 by the Society for Reproduction and Development

Correspondence: L-Y Cai (e-mail: caili76@hotmail.co.jp)

*L-Y Cai and T Kato contributed equally to this work. enzymatic activity of HSV1-TK produced [5]. However, precise morphological analyses of the seminiferous tubules of HSV1-TK transgenic mice have not yet been reported.

We previously reported that HSV1-TK transgenic rats also show male infertility by the ectopic spermatid-specific ectopic expression of HSV1-TK gene [7]. We have identified the testis-specific transcription start site of the HSV1-TK gene to produce two types of truncated TK polypeptides that retain enzymatic activity [8]. These TK molecules were accumulated in the postmeiotic spermatids, resulting in disruption of spermatid-stage-specific maturation in young transgenic rats and leading to an age-dependent apoptotic loss of germ cells in adult transgenic rats [8].

Although it is well known that HSV1-TK transgenic animals suffer from male infertility, the molecular mechanisms underlying the disruption of spermiogenesis by ectopic expression of the HSV1-TK gene in postmeiotic spermatids have not yet been clarified. Furthermore, the mechanisms leading to apoptotic germ cell loss by HSV1-TK expressed in spermatids are largely unknown. To better understand the severity and toxic role of HSV1-TK in the spermatogenesis injury caused by HSV1-TK, we performed detailed morphological 
Table 1. Primer sequences for real-time PCR analyses of gene expression

\begin{tabular}{|c|c|c|c|c|}
\hline \multirow{2}{*}{ Gene symbol } & \multirow{2}{*}{ Accession no. } & \multicolumn{2}{|c|}{ Primer sequence ( $\left.5^{\prime}-3^{\prime}\right)$} & \multirow{2}{*}{ Size (bp) } \\
\hline & & Forward & Reverse & \\
\hline Cnot7 & NM_001107313 & CTGACTCACTGCTTACAGGA & ATAGGATGAGCCAGAACCAA & 119 \\
\hline Fgf7 & NM_022182 & GGGGTGGAAAGTGAATACTATC & TGATGCAGAGGTGTTGTAATGG & 126 \\
\hline Egfl6 & NM_001108254 & GTGGAAGACAGGAAAAGTCC & CCATCCACTGCAATTTCTCC & 108 \\
\hline Testin & NM_173132 & GAAGAATCAGATGGCAACAG & ATATGTAGCAATCCCGCAGT & 120 \\
\hline Ostf1 & NM_148892 & GTGCATCGCTCCTGAAGAAGAA & CATCGAGGTAGTCCTCAGCATT & 75 \\
\hline Atp2a2 & NM_001110139 & GCTTGTCCATGTCCCTTCAC & GGATCACAGGCAGGGAGATT & 123 \\
\hline Sh3bp4 & NM_022693 & GCAACAGATGGATGCCTATG & TGGTGGCTCCAGGTGAGTAA & 108 \\
\hline Lamc2 & NM_001100640 & ATCCTGCGCCTAATAGACCA & CCTCCAGTTCAGACATCAAG & 127 \\
\hline Vcan & NM_001170558 & AAACAAGCACGGAACCATCG & CATAGGACCAACCCCAGTCT & 115 \\
\hline Mamdc1 & NM_199269 & GGAGAATGTGCAAAACAAGAC & AGGGCTTAAGATCGAGATGAG & 114 \\
\hline$T B P$ & NM_001004198 & CTTCGTGCCAGAAATGCTGAATA & TGTTCTTCACTCTTGGCTCCTGT & 134 \\
\hline
\end{tabular}

observations and cDNA microarray analyses. We observed severe dysmorphogenesis in the seminiferous epithelium and epididymal lumen by transmission electron microscopy in 3-month-old transgenic rats and significant changes in the expression of genes related to Sertoli-germ cell adhesions.

\section{Materials and Methods}

\section{Experimental animals}

HSV1-TK transgenic rats were generated using Fischer 344 rats [8]. Since the produced transgenic rats showed male infertility, heterozygote offspring were obtained by crossing a transgenic female rat with a normal male rat. The animals were individually housed in standard plastic rodent cages in a temperature-controlled environment with standard rat diet and water available ad libitum in a 12-h light/ dark cycle [9]. The experimental procedures were approved by the Institutional Animal Care and Use Committee of Meiji University.

Light microscope and transmission electron microscopy (TEM)

The testes and cauda epididymides were isolated from wild-type and transgenic rats at 3 months (each $n=2)$ of age and fixed overnight in $2.5 \%$ glutaraldehyde and $0.05 \mathrm{M}$ phosphate buffer $(\mathrm{PB} ; \mathrm{pH} 7.4)$ at $4 \mathrm{C}$. The samples were washed in $0.1 \mathrm{M} \mathrm{PB}$ and fixed in $1 \%$ osmium tetroxide/0.05 M PB for $3 \mathrm{~h}$ at $4 \mathrm{C}$. After fixation, the samples were embedded in epoxy resin, and semi-thin $(1 \mu \mathrm{m})$ and thin $(75 \mathrm{~nm})$ sections were cut with an ultramicrotome. The semi-thin sections were stained with toluidine blue for light microscopic examination (BZ-8000; Keyence, Osaka, Japan). The thin sections were dehydrated with serial graded ethanol and acetone and embedded in Epon, followed by staining with uranylacetate, post-staining with lead citrate and analysis by TEM (JEOL JEM1200EX2 electron microscopy, Tokyo, Japan) at an accelerating voltage of $80 \mathrm{kV}$.

\section{Total RNA preparation}

Testes from 3-month-old wild-type and transgenic rats (each $n=4$ ) were homogenized in Isogen RNA extraction reagent (Nippon Gene, Tokyo, Japan) with a Polytron homogenizer for $15 \mathrm{sec}$, and total RNA was prepared from homogenized tissue according to the manufacturer's instructions. Residual DNAs were digested with RQ1
RNase-Free DNase (Promega, Madison, WI, USA).

\section{cDNA microarray}

cDNA microarrays were performed using a custom analysis service (Kurabo Industries, Osaka, Japan), which was an authorized service provider using the Affymetrix array (Affymetrix Japan, Tokyo, Japan). In brief, the quality of RNA samples was checked using a 2100 Bioanalyzer (Agilent, Santa Clara, CA, USA). Ten micrograms of total RNA, a mixture of $2.5 \mu \mathrm{g}$ from each of four individuals, was subjected to microarray hybridization using the GeneChip Rat Genome 2302.0 Array (Affymetrix), which consists of over 31,000 probe sets and represents over 28,000 well-substantiated rat genes. Raw intensity data from the GeneChip array were analyzed with GeneChip Operating Software (Affymetrix).

\section{Real-time PCR}

Real-time PCR was performed. Briefly, $3 \mu \mathrm{g}$ total testis RNA from 3-month-old wild-type and transgenic rats (each $n=4$ ) was reverse-transcribed using PrimeScript Reverse transcriptase (Takara Bio., Siga, Japan) to confirm the results of cDNA microarray. cDNAs were analyzed in a $20 \mu 1$ reaction volume containing a set of primers (Table 1) and $10 \mu$ l of SYBR Green PCR Master Mix (Toyobo, Osaka, Japan) using a 7500 Real-Time PCR System (Applied Biosystems, Foster, CA, USA) according to the manufacturer's recommendations. The relative expression level of each gene was normalized and quantified to that of TATA-box binding protein (TBP) as an internal control using RQ software (Applied Biosystems).

\section{Results}

Ultrastructural analysis of seminiferous tubules and germ cells Normal spermatogenesis was confirmed by light microscopic observation of the seminiferous tubules and the epididymides of 3-month-old wild-type rats (Fig. 1A and B). In contrast, transgenic rats revealed particular morphological alterations both in the seminiferous tubules and the epididymides (Fig. 1C and D). These disorders included a lower population of spermatogenic cells (spermatogonia, spermatocytes and round and elongated spermatids) in the seminiferous tubules (Fig. 1C) and fewer spermatozoa in the lumen of the 

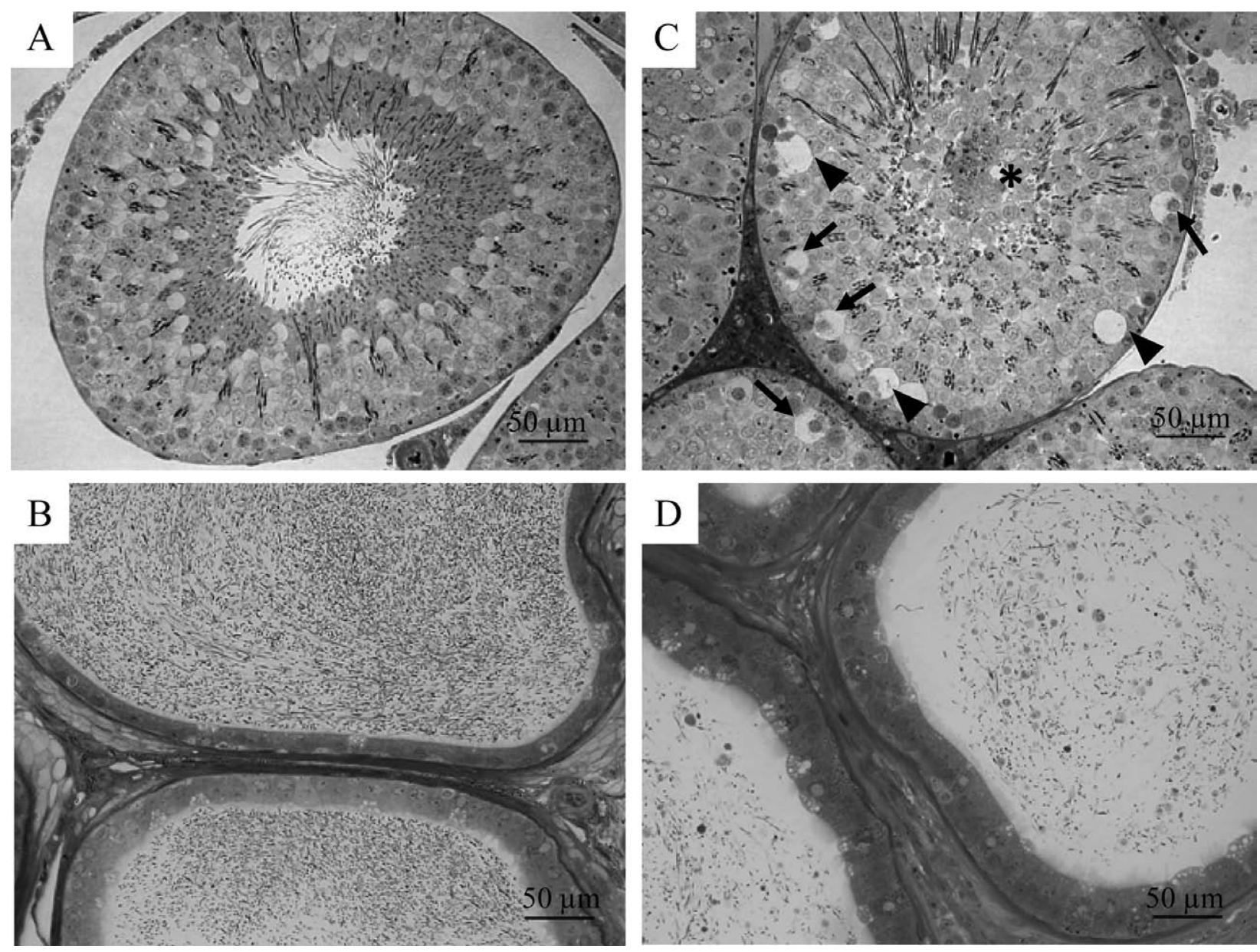

Fig. 1. Morphological alterations in 3-month-old transgenic rats. Toluidine blue-staining was performed for seminiferous tubules (A and C) and cauda epididymides (B and D) of wild-type (A and B) and transgenic rats (C and D). Vacuoles were visible in tubules (C, arrowheads), and degenerating spermatogenic cells were frequently observed (C, arrows). Consequently, a large number of immature and degenerating spermatogenic cells were sloughed into the lumen of seminiferous tubules (C, asterisk) and were eventually pooled in the epididymis (D).

epididymis (Fig. 1D) than in the wild-type rats (Fig. 1A and B). In addition, vacuolization in the seminiferous epithelium (Fig. 1C, arrowhead), degenerating spermatogenic cells (Fig. 1C, arrow), many exfoliated immature and degenerated spermatogenic cells (Fig. 1C, asterisk) and accumulation of immature spermatogenic cells in the epididymides (Fig. 1D) were observed.

We then performed ultrastructural analysis of seminiferous tubules to identify the spermatogenic cell type using TEM. When compared with the results of the 3-month-old wild-type rats (Fig. $2 \mathrm{~A}-\mathrm{C})$, massive vacuoles were observed within the seminiferous epithelium of transgenic rat testes (Fig. 2D and E, asterisk). While spermatocytogenesis and meiosis were confirmed, degenerating spermatocytes were frequently observed in the seminiferous tubules of the transgenic rats (Fig. 2E and F, arrowhead). Moreover, in the lumen of the seminiferous tubule, elongated spermatids showing disorganized heads with a disruption of the cell membrane (Fig. 2G, arrowhead) and multiple flagella (Fig. 2H and I, arrow) were observed.

Ultrastructural analysis of the epididymides of 3-month-old wild-type rats showed intact cell membranes and normal-shaped heads with complete chromatin condensation of the spermatozoa (Fig. 3A1). However, the number of spermatozoa in the epididymis of transgenic rats was lower than that in wild-type rats (Fig. 3A and B). In addition, a large number of immature spermatids detaching from Sertoli cells and sloughing into the epididymides were observed (Fig. 3B1-4). Degenerated round spermatid (Fig. 3B1) and many types of abnormal elongated spermatids (Fig. 3B2-4) were frequently observed. In contrast to the normally assembled flagellar axonemes composed of nine outer doublet microtubules and a pair of central microtubules (Fig. 3A2), most spermatozoa from the transgenic rats were dead and showed various ultrastructural defects including breakage of the surface membrane (Fig. 3B5) and a decline in the number of outer dense fibers (Fig. 3B6).

\section{Alterations in gene expression profiles in transgenic rat testes}

cDNA microarray analysis was performed to examine alterations in gene expression evoked by HSV1-TK accumulation in transgenic rat testes. As a result, a total of two hundred genes $(0.67 \%$ of all transcripts represented on the chips) had changed in expression level 

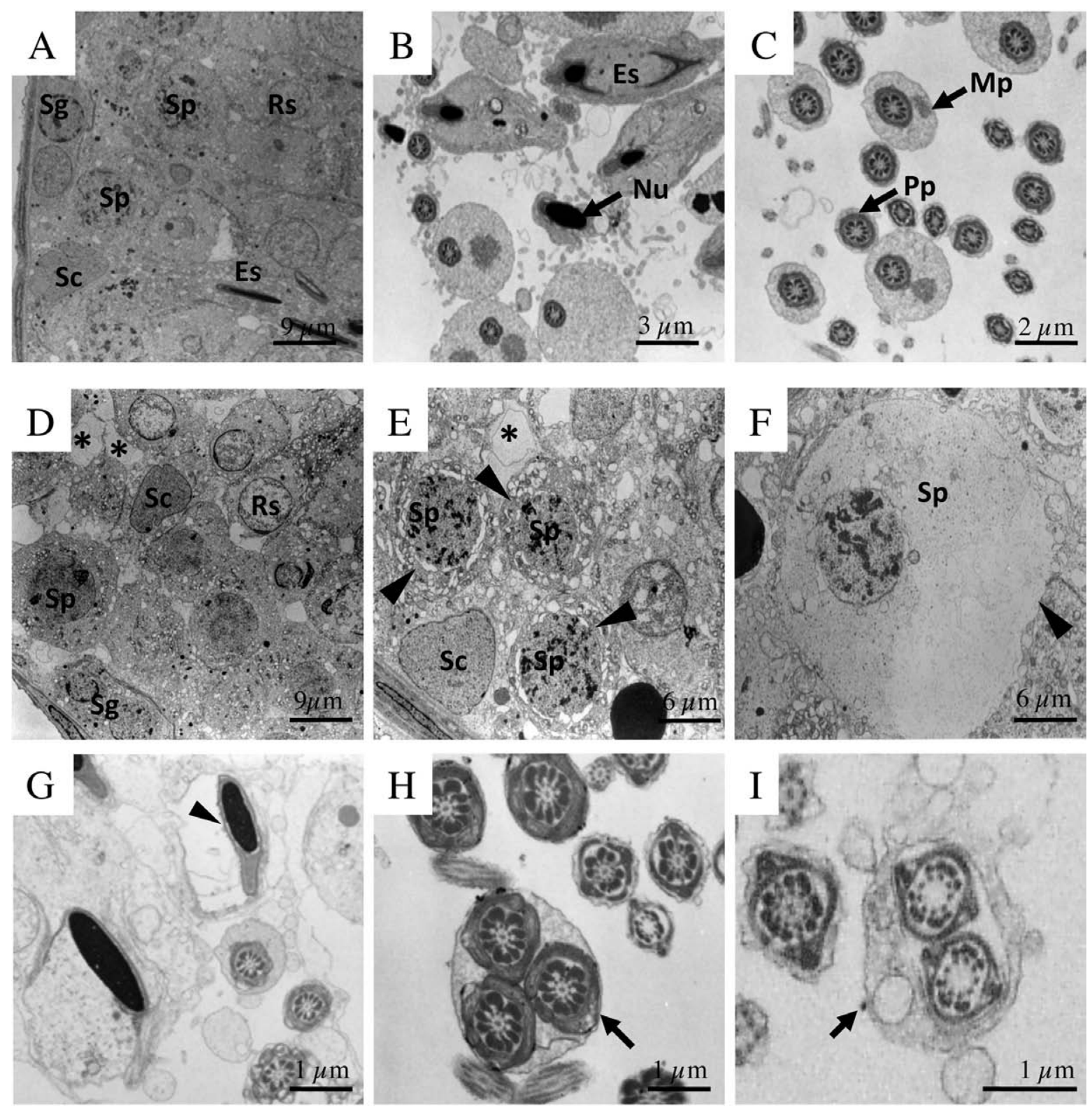

Fig. 2. Transmission electron microscopic observation of spermatogenesis in 3-month-old wild-type and transgenic rats. Wild-type rats show a normal process of spermatogenesis $(\mathrm{A}-\mathrm{C})$. Normal nuclear condensation $(\mathrm{Nu})$, the midpiece $(\mathrm{Mp})$ and the principle piece $(\mathrm{Pp})$ are indicated by arrows. In the transgenic rats, massive vacuoles are present within the seminiferous epithelium (D and $\mathrm{E}$, asterisk) together with degeneration in spermatocytes (E and F, arrowhead). Elongated spermatids within the lumen of seminiferous tubules show various ultrastructural abnormalities including disorganized heads with disrupted cell membranes $(\mathrm{G}$, arrowhead) and multiple flagella (H and I, arrow). Sg, spermatogonia; Sp, spermatocyte; Sc, Sertoli cell; Rs, round spermatid; Es, elongated spermatid.

in the HSV1-TK transgenic rats in comparison with those of the wild-type rats. First, the altered genes were sorted by their functional categories including apoptosis, cell cycle, development, oxidative stress, proteolysis, signal transduction, transcription, translation, transport, immune response, metabolism and cell adhesion (Table 2). There were great numbers of affected genes in the metabolism (24 genes), transport (23 genes) and development (19 genes) categories. Of all of the altered genes, twenty-seven were upregulated and twenty-two were downregulated by at least 1.5 -fold in the transgenic rat testis. We selected 10 genes $(\operatorname{cnot} 7$, fgf7, egfl6, testin, ostf1 and atp2a 2 from upregulated genes, and sh3bp4, lamc2, versican and mamdc 1 from downregulated genes) of interest for their roles in cell adhesion, signal transduction, transport and development (the category of each gene is listed in Table 3). To confirm the microarray data, the gene expression levels were quantified by real-time PCR. As shown in Table 3, upregulation in genes cnot7, fgf7, testin and 

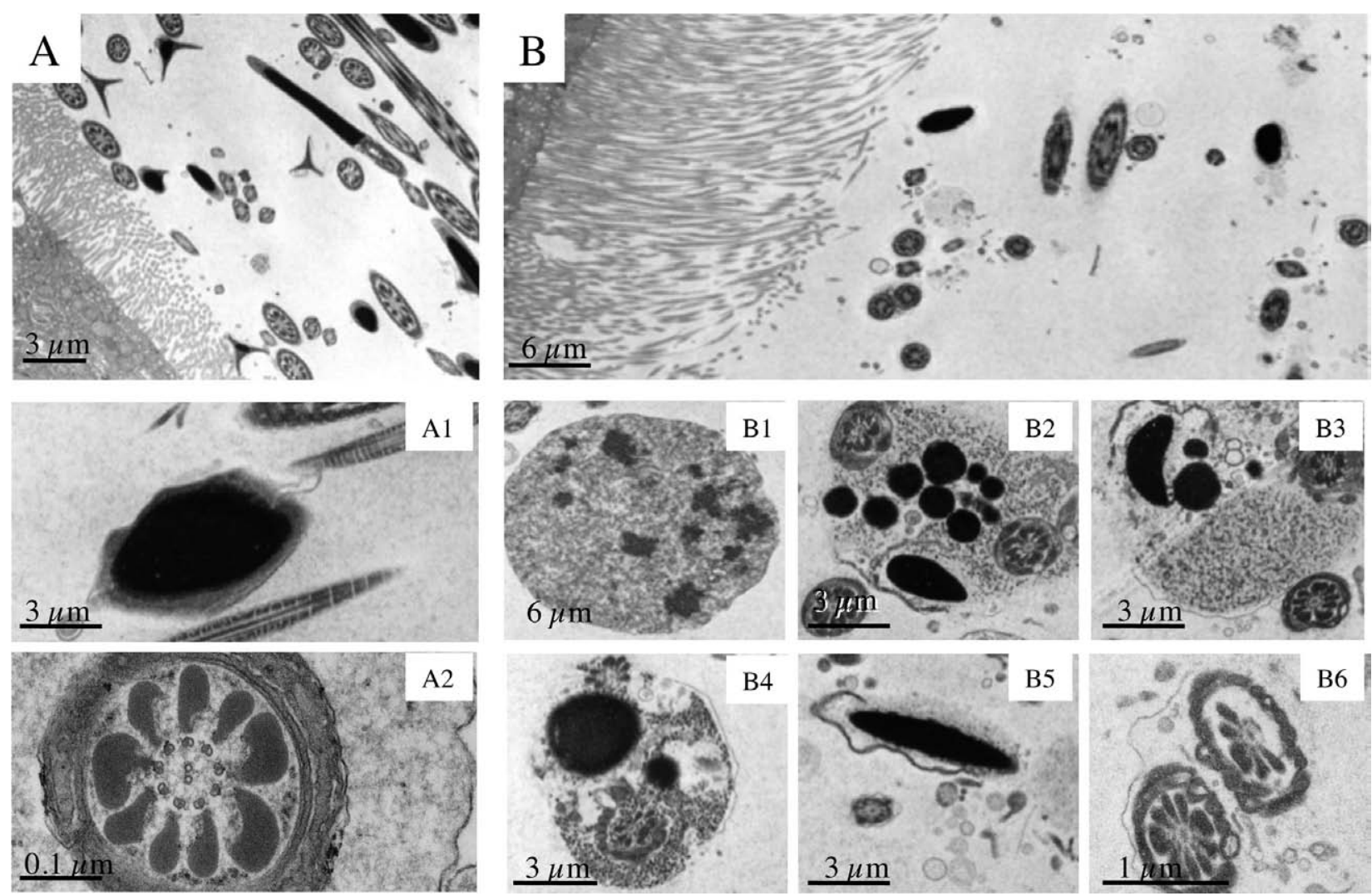

Fig. 3. Transmission electron microscopic observation of the epididymides from 3-month-old wild-type and transgenic rats. (A) Spermatozoa from wild-type rats show normal condensed nuclei with intact acrosomes (A1) as well as normally assembled flagellar axonemes comprised of nine outer doublet microtubules and a pair of central microtubules (A2). (B) In the epididymides of the transgenic rat, degenerating round spermatids (B1) and many types of abnormal elongated spermatids (B2-4) were frequently observed. Abnormal spermatozoa showing a breakage of surface membranes (B5) and decline in the member of outer dense fiber were also observed (B-6).

Table 2. Number of affected genes in testes of HSV1-TK transgenic rats revealed by cDNA microarray

\begin{tabular}{lccc}
\hline \multirow{2}{*}{ Biological process } & \multicolumn{3}{c}{ Changes in number of genes expressed } \\
\cline { 2 - 4 } & Decreased & Increased & Total \\
\hline Apoptosis & 1 & 4 & 5 \\
Cell cycle & 2 & 4 & 6 \\
Development & 3 & 16 & 19 \\
Oxidative stress & 0 & 1 & 1 \\
Proteolysis & 3 & 7 & 10 \\
Signal transduction & 2 & 11 & 13 \\
Transcription & 6 & 6 & 12 \\
Translation & 1 & 1 & 2 \\
Transport & 12 & 11 & 23 \\
Immune response & 1 & 2 & 3 \\
Metabolism & 8 & 16 & 24 \\
Cell adhesion & 3 & 4 & 7 \\
Other & 54 & 21 & 75 \\
Total & 96 & 104 & 200 \\
\hline The
\end{tabular}

The affected genes were classified into 12 functional categories according to "Gene Ontology". ostf1 and downregulation in versican and mamdc1 were significantly consistent with the microarray data.

\section{Discussion}

We previously reported that the spermiogenesis of 10 -week-old HSV1-TK transgenic rats is disrupted, while the processes of spermatocytogenesis and spermatidogenesis are likely to be completed [8]. The present study demonstrated the disruption of all stages of spermatogenesis predicted by histopathological alterations in 3 -month-old transgenic rats. These disorders were marked in terms of seminiferous epithelial sloughing, vacuolization and degeneration in spermatocytes in addition to abnormal elongated spermatids and spermatozoa in the seminiferous lumen.cDNA microarray and realtime PCR analyses revealed that the expression levels of four genes (cnot7, fgf7, testin and ostf1) significantly increased $(\mathrm{P}<0.05)$ and that those of two genes (versican and mamdc1) decreased $(\mathrm{P}<0.05)$.

Loss of testicular function is caused by various mechanisms such as antiandrogenic effects of phthalate esters in rats [10] and fish [11], disruption of microtubule dynamics by Sertoli cell toxicants [12-16], disruption of $\mathrm{Ca}^{2+}$ homeostasis [17], disruption of the blood-testis barrier via the mitogen-activated protein kinase signaling pathway 
Table 3. Expression level of genes assayed by microarray analysis and real-time PCR

\begin{tabular}{|c|c|c|c|c|c|}
\hline \multicolumn{3}{|l|}{ Gene product } & \multirow{2}{*}{$\begin{array}{c}\text { Microarray analysis } \\
\text { Ratio of TG } \\
\text { value/ } \mathrm{N} \text { value }\end{array}$} & \multicolumn{2}{|c|}{ Real-time PCR results } \\
\hline Gene title & $\begin{array}{c}\text { Gene } \\
\text { symbol }\end{array}$ & Category & & $\begin{array}{c}\text { Expression } \\
\text { levels TG/N }\end{array}$ & P value \\
\hline \multicolumn{6}{|l|}{ Upregulated genes in TG rat testes } \\
\hline CCR4-NOT transcription complex, subunit 7 & Cnot7 & Signal transduction & 18.40 & 1.30 & $<0.05$ \\
\hline Fibroblast growth factor 7 & $F g f 7$ & Development & 6.10 & 2.00 & $<0.05$ \\
\hline EGF-like-domain, multiple 6 & Egfl6 & Cell adhesion & 3.70 & 0.91 & NS \\
\hline Testin gene & Testin & Cell adhesion & 2.30 & 2.00 & $<0.05$ \\
\hline Osteoclast stimulating factor 1 & Ostf1 & Transcription & 1.68 & 1.30 & $<0.05$ \\
\hline ATPase, $\mathrm{Ca}^{++}$transporting, cardiac muscle, slow twitch 2 & Atp2a2 & Transport & 1.67 & 0.96 & NS \\
\hline \multicolumn{6}{|l|}{ Down-regulated genes in TG rat testes } \\
\hline SH3-domain binding protein 4 & Sh $3 b p 4$ & Cell adhesion & 0.06 & 0.91 & NS \\
\hline Lamimin, gamma 2 & Lamc2 & Cell adhesion & 0.09 & 0.90 & NS \\
\hline Chondroitin sulfate proteoglycan 2 & Versican & Cell adhesion & 0.10 & 0.55 & $<0.05$ \\
\hline MAM domain containing glycosylphosphatidylinositol anchor 2 & Mamdc1 & Cell adhesion & 0.62 & 0.67 & $<0.05$ \\
\hline
\end{tabular}

by cadmium [18], and induction of germ cell apoptosis via the Fas/FasL signaling pathway [19]. Mono-(2-ethylhexyl) phthalate (MEHP) is known as a Sertoli cell toxicant. Giammona et al. reported that germ cell-associated death receptors, Fas and TRAIL-R2 (DR5), which participate in the regulation of germ cell apoptosis, appear to be responsive to MEHP-induced Sertoli cell injury[20]. Hild et al. administered indenopyridine CDB-4022 (a nonsteroidal male oral contraceptive) to normal rats and demonstrated that this contraceptive disrupts spermatogenesis by inducing apoptosis in early-stage germ cells via direct action on the Sertoli cells [21]. In these cases described above, histopathological changes caused by disruption of spermatogenesis are marked in terms of seminiferous epithelial sloughing, vacuolization, germ cell apoptosis and germ cell loss in the seminiferous tubules as shown in this study and our previous reports $[7,8]$.

Masuda et al. [22] reported ultrastructural studies on cytotoxic effects of cyclosporine $\mathrm{A}$ in spermiogenesis in rats exhibiting degeneratin ground spermatids, abnormal spermatozoa and residual bodies containing numerous flagella in the epididymal lumen as shown in the present study. They speculated regarding direct impairments to spermiogenic cell development and indirect effects on Sertoli cell functions including reduction of phagocytic activity by cyclosporine A. These findings described above findings suggested that the morphological alterations observed are common in testes containing injured germ cells and Sertoli cells, indicating that disruption of spermatogenesis is caused by destruction of Sertoli-germ cell adhesions. In the current study, cDNA microarray analysis was performed to better understand the underlying molecular mechanisms of HSV1-TK proteins that interfere with spermatogenesis. From 200 genes affected by the HSV1-TK, we selected 10 genes and subjected them to quantitative real-time PCR to confirm the microarray data. The results revealed that the cell adhesion-associated genes, testin, versican, and mamdc1, were significantly altered in their expression levels $(\mathrm{P}<0.05)$ in the transgenic rat testes. Testin protein is considered to be a signaling molecule for monitoring Sertoli-germ cell adherens junctions (AJs), and the increased secretion of testin by Sertoli cells is in response to the disruption of Sertoli-germ cell
AJs [23, 24]. The expression of versican was detected in the adult mouse brain, heart, lung, spleen, skeletal muscle, skin, tail, kidney and testis. Versican reportedly may play a role in cellular attachment, migration and proliferation by interacting with cell surfaces and extracellular matrix molecules [25]. The mamdc1 gene is expressed in human Leydig cells of the testis. Mamdc1 mRNA was upregulated by pro-inflammatory cytokines such as TNF- $\alpha$ and IFN- $\gamma$ [26]. Mamdc1 appears to be a novel member of the adhesion molecules of the immunoglobulin superfamily (IgCAM), which is involved in cell adhesion, migration and recruitment to inflammatory sites [26]. The function of versican and mamdc1 proteins in spermatogenesis is yet obscure. On the other hand, the increased expression of growth factors, such as growth factor fgf7, osteoclast stimulating factor ostfl and cell proliferation factor cnot7 [27], may be a stress response in the transgenic rat testes. Among these results, our focus was ontestin, which is localized near the Sertoli cell surface in the testis where Sertoli and germ cells interact [28, 29].

Recently, the mechanisms of male infertility targeted by adjudin, a contraceptive that displays the same morphogenic alterations in the seminiferous tubules as described above, have reportedly caused disruption of Sertoli-germ cell AJs by targeting directly testin protein and actin-myosin [30]. Our results showing that the expression level of testin gene increases in 3-month-old transgenic rats suggested that disruption of Sertoli-germ cell AJs occurred and triggered the derangement of spermatogenesis. Taking the findings and results of previous studies together with those of the present study including histopathological observations and microarray analysis, it is suggested that the accumulation of HSV1-TK in the spermatids first affects spermiogenesis and later disrupts all stages of spermatogenesis through an impairment of Sertoli-germ cell AJs resulting in apoptotic germ cell loss. However, the roles of HSV1-TK in these phenomena must be clarified in the near future.

It is worth noting that an accumulation of evidence has demonstrated that HSV infection in humans has a negative effect on male reproduction [31-35]. HSV infection, a type of sexually transmitted disease caused by HSV-1 and HSV-2, results in low sperm counts, poor sperm motility, spontaneous abortions and failure 
of artificial insemination $[33,35]$. In their morphology, spermatozoa showed micro-heads, cytoplasm drops on the neck [34] and possible apoptotic spermatogenic cells[36]. Previous studies in HSV1-TK transgenic animals have demonstrated that the spermatid-specific ectopic expression of the HSV1-TK gene in the testes oftransgenic animalsis controlled under the testicular cryptic promoter within the HSV1-TK gene [5, 8]. Therefore, we have hypothesized that the HSV1-TK gene might be expressed in the testes of HSV1-infected humans and cause male infertility. Clarification of the target of HSV1-TK protein in transgenic animals and exploration of whether the HSV1-TK gene is expressed in HSV-infected patients could be worthwhile and important for a better understanding of the correlation between HSV1-TK function and male infertility.

In summary, we here provide evidence for morphological changes associated with a disruption of Sertoli-germ cell AJs and alterations in gene expression occurring in HSV1-TK transgenic rats. We propose that the accumulation of HSV1-TK proteins in postmeiotic spermatids interferes with not only spermiogenesis but also all processes of spermatogenesis through disruption of Sertoli-germ cell AJs. Further studies are warranted to explore the action of HSV1-TK protein in testicular cells and its link to HSV-infected male infertility in humans.

\section{Acknowledgments}

This research was partially supported by the Japanese Ministry of Education, Culture Sports, Science and Technology, Grants-inAid for Scientific Research (B) Nos. 0645401909 and 21380184, by the Institute of Science and Technology, Meiji University and by a Grant-in-Aid for Scientific Research (A) to YK. Our study was also supported by a "High-Tech Research Center" Project for Private Universities: matching fund subsidy, 2006-2008, from the Ministry of Education, Culture, Sports, Science and Technology of Japan. The authors wish to thank Mr A Akatsuka, the Division of Basic Clinical Science, Department of Regenerative Medicine, Tokai University School of Medicine, for his technical assistance.

\section{References}

1. Greco O, Dachs GU. Gene directed enzyme/prodrug therapy of cancer: historical appraisal and future prospectives. $J$ Cell Physiol 2001; 187: 22-36. [Medline] [CrossRef]

2. Spencer DM. Developments in suicide genes for preclinical and clinical applications. Curr Opin Mol Ther 2000; 2: 433-440. [Medline]

3. Al-Shawi R, Burke J, Jones CT, Simons JP, Bishop JO. A Mup promoter-thymidine kinase reporter gene shows relaxed tissue-specific expression and confers male sterility upon transgenic mice. Mol Cell Biol 1988; 8: 4821-4828. [Medline]

4. Braun RE, Lo D, Pinkert CA, Widera G, Flavell RA, Palmiter RD, Brinster RL. Infertility in male transgenic mice: disruption of sperm development by HSV-tk expression in postmeiotic germ cells. Biol Reprod 1990; 43: 684-693. [Medline]

5. al-Shawi R, Burke J, Wallace H, Jones C, Harrison S, Buxton D, Maley S, Chandley A, Bishop JO. The herpes simplex virus type 1 thymidine kinase is expressed in the testis of transgenic mice under the control of a cryptic promoter. Mol Cell Biol 1991; 11: 4207-4216. [Medline]

6. Huttner KM, Pudney J, Milstone DS, Ladd D, Seidman JG. Flagellar and acrosomal abnormalities associated with testicular HSV-tk expression in the mouse. Biol Reprod 1993; 49: 251-261. [Medline]

7. Cai LY, Kato T, Ito K, Nakayama M, Susa T, Aikawa S, Maeda KI, Tsukamura H, Ohta A, Izumi SI, Kato Y. Expression of porcine FSH $\beta$ subunit promoter-driven herpes simplex virus thymidine kinase gene in transgenic rats. J Reprod Dev 2007; 53: 201-209. [Medline] [CrossRef]

8. Cai LY, Kato T, Nakayama M, Susa T, Izumi SI, Kato Y. HSV type 1 thymidine kinase protein accumulation in round spermatids induces male infertility by spermatogenesis disruption and apoptotic loss of germ cells. Reprod Toxicol 2009; 27: 14-21. [Medline] [CrossRef]

9. Kobayashi T, Shirai M, Sakaue M, Murakami M, Ochiai H, Arishima K, Yamamoto M. Effects of maternal exposure to low doses of DES on testicular steroidogenesis and spermatogenesis in male rat offspring. J Reprod Dev 2009; 55: 629-637. [Medline] [CrossRef]

10. Howdeshell KL, Wilson VS, Furr J, Lambright CR, Rider CV, Blystone CR, Hotchkiss AK, Gray LE Jr. A mixture of five phthalate esters inhibits fetal testicular testosterone production in the sprague-dawley rat in a cumulative, dose-additive manner. Toxicol Sci 2008; 105: 153-165. [Medline] [CrossRef]

11. Aoki KA, Harris CA, Katsiadaki I, Sumpter JP. Evidence suggesting that di-n-butyl phthalate has antiandrogenic effects in fish. Environ Toxicol Chem 2011; 30: 1338-1345. [Medline] [CrossRef]

12. Russell LD, Malone JP, MacCurdy DS. Effect of the microtubule disrupting agents, colchicine and vinblastine, on seminiferous tubule structure in the rat. Tissue Cell 1981; 13: 349-367. [Medline]

13. Markelewicz RJ Jr, Hall SJ, Boekelheide K. 2,5-hexanedione and carbendazim coexposure synergistically disrupts rat spermatogenesis despite opposing molecular effects on microtubules. Toxicol Sci 2004; 80: 92-100. [Medline] [CrossRef]

14. Andriana BB, Tay TW, Tachiwana T, Sato T, Ishii M, Awal MA, Kanai Y, Kurohmaru M, Hayashi Y. Effects of mono (2-ethylhexyl) phthalate (MEHP) on testes in rats in vitro. Okajimas Folia Anat Jpn 2004; 80: 127-136. [Medline] [CrossRef]

15. Moffit JS, Bryant BH, Hall SJ, Boekelheide K. Dose-dependent effects of sertoli cell toxicants 2,5-hexanedione, carbendazim, and mono-(2-ethylhexyl) phthalate in adult rat testis. Toxicol Pathol 2007; 35: 719-727. [Medline] [CrossRef]

16. Hess RA, Nakai M. Histopathology of the male reproductive system induced by the fungicide benomyl. Histol Histopathol 2000; 15: 207-224. [Medline]

17. Laurentino SS, Correia S, Cavaco JE, Oliveira PF, Rato L, Sousa M, Barros A, Socorro $\mathbf{S}$. Regucalcin is broadly expressed in male reproductive tissues and is a new androgen-target gene in mammalian testis. Reproduction 2011; 142: 447-456. [Medline] [CrossRef]

18. Zhao XF, Wang Q, Ji YL, Wang H, Liu P, Zhang C, Zhang Y, Xu DX. Fenvalerate induces germ cell apoptosis in mouse testes through the Fas/FasL signaling pathway. Arch Toxicol 2011; 85: 1101-1108. [Medline] [CrossRef]

19. Siu ER, Mruk DD, Porto CS, Cheng CY. Cadmium-induced testicular injury. Toxicol Appl Pharmacol 2009; 238: 240-249. [Medline] [CrossRef]

20. Giammona CJ, Sawhney P, Chandrasekaran Y, Richburg JH. Death receptor response in rodent testis after mono-(2-ethylhexyl) phthalate exposure. Toxicol Appl Pharmacol 2002; 185: 119-127. [Medline] [CrossRef]

21. Hild SA, Reel JR, Larner JM, Blye RP. Disruption of spermatogenesis and Sertoli cell structure and function by the indenopyridine CDB-4022 in rats. Biol Reprod 2001; 65 1771-1779. [Medline] [CrossRef]

22. Masuda H, Fujihira S, Ueno H, Kagawa M, Katsuoka Y, Mori H. Ultrastructural study on cytotoxic effects of cyclosporine A in spermiogenesis in rats. Med Electron Microsc 2003; 36: 183-191. [Medline] [CrossRef]

23. Cheng CY, Silvestrini B, Grima J, Mo MY, Zhu LJ, Johansson E, Saso L, Leone MG, Palmery M, Mruk D. Two new male contraceptives exert their effects by depleting germ cells prematurely from the testis. Biol Reprod 2001; 65: 449-461. [Medline] [CrossRef]

24. Cheng CY, Mruk DD. Cell junction dynamics in the testis: Sertoli-germ cell interactions and male contraceptive development. Physiol Rev 2002; 82: 825-874. [Medline]

25. Naso MF, Morgan JL, Buchberg AM, Siracusa LD, Iozzo RV. Expression pattern and mapping of the murine versican gene (Cspg2) to chromosome 13. Genomics 1995; 29: 297-300. [Medline] [CrossRef]

26. Hellquist A, Zucchelli M, Lindgren CM, Saarialho-Kere U, Jarvinen TM, Koskenmies S, Julkunen H, Onkamo P, Skoog T, Panelius J, Raisanen-Sokolowski A, Hasan T, Widen E, Gunnarson I, Svenungsson E, Padyukov L, Assadi G, Berglind L, Makela VV, Kivinen K, Wong A, Cunningham Graham DS, Vyse TJ, D'Amato M, Kere J. Identification of MAMDC1 as a candidate susceptibility gene for systemic lupus erythematosus (SLE). PLoS ONE 2009; 4: e8037. [Medline] [CrossRef]

27. Aslam A, Mittal S, Koch F, Andrau JC, Winkler GS. The Ccr4-NOT deadenylase subunits CNOT7 and CNOT8 have overlapping roles and modulate cell proliferation. $\mathrm{Mol}$ Biol Cell 2009; 20: 3840-3850. [Medline] [CrossRef]

28. Grima J, Zwain I, Lockshin RA, Bardin CW, Cheng CY. Diverse secretory patterns of clusterin by epididymis and prostate/seminal vesicles undergoing cell regression after orchiectomy. Endocrinology 1990; 126: 2989-2997. [Medline] [CrossRef]

29. Grima J, Pineau C, Bardin CW, Cheng CY. Rat Sertoli cell clusterin, alpha 2-macroglobulin, and testins: biosynthesis and differential regulation by germ cells. Mol Cell Endocrinol 1992; 89: 127-140. [Medline] [CrossRef]

30. Mruk DD, Cheng CY. Testin and actin are key molecular targets of adjudin, an anti-spermatogenic agent, in the testis. Spermatogenesis 2011; 1: 137-146. [Medline] [CrossRef]

31. el Borai N, Inoue M, Lefevre C, Naumova EN, Sato B, Yamamura M. Detection of 
herpes simplex DNA in semen and menstrual blood of individuals attending an infertility clinic. J Obstet Gynaecol Res 1997; 23: 17-24. [Medline]

32. Kotronias D, Kapranos N. Detection of herpes simplex virus DNA in human spermatozoa by in situ hybridization technique. In vivo 1998; 12: 391-394. [Medline]

33. Kapranos N, Petrakou E, Anastasiadou C, Kotronias D. Detection of herpes simplex virus, cytomegalovirus, and Epstein-Barr virus in the semen of men attending an infertility clinic. Fertil Steril 2003; 79(Suppl 3): 1566-1570. [Medline] [CrossRef]

34. Abdulmedzhidova AG, Kurilo LF, Shileiko LV, Makarova NP, Klimova RR, Kushch AA. Asymptomatic genital herpes infection and infertility in males. Urologiia 2007; May-
Jun: 56-59. [Medline]

35. Bocharova EN, Bragina EE, Gusak Iu K, Zotov VV, Tereshchenko AB, Shileiko LV, Kurilo LF, Klimova RR, Kushch AA. Herpetic infection of spermatozoa in failure of reproductive technologies and spontaneous abortion. Urologiia 2007; May-Jun: 59-63. [Medline]

36. Wu KH, Zhou QK, Huang JH, Lai RQ, Lin FH, Li B, Zhang CB, Zhou WN, Zhu ZP. Infection of cytomegalovirus and herpes simplex virus and morphology of the infected spermatogenic cells in infertile men. Zhonghua Nan Ke Xue 2007; 13: 1075-1079. [Medline] 